\title{
Sobre crânios, idiomas e artefatos indígenas: 0 colecionismo e a História Natural na viagem de Johann Natterer ao Brasil (1817-1835)
}

\author{
Rita de Cássia Melo Santos \\ Professora Doutora da Universidade Federal da Paraíba, João Pessoa, Brasil \\ santos.cm.rita@gmail.com
}

Resumo $\mathrm{O}$ presente artigo busca explorar as práticas colecionistas de crânios, idiomas e artefatos indígenas empreendidas por Johann Natterer em sua viagem ao Brasil (1817-1835). Realizada no âmbito da comissão científica austríaca (maior empreendimento científico até então realizado), Natterer foi pioneiro na formação de coleções na região do Mato Grosso e Rio Negro. Dada a dimensão de sua viagem, para o artigo apresentado foram selecionados três grandes conjuntos de situações etnográficas que permitem refletir sobre o uso generalizado da categoria 'naturalista' para indexar coleções coproduzidas por uma rede de atores sociais desigualmente posicionados socialmente: indígenas (livres e escravos), chefes de milícias, tenentes, governadores de província etc. Além de pluralizar a categoria 'naturalista', o artigo se propõe ainda a pensar as conexões entre o colecionismo no âmbito da História Natural e a etnografia.

Palavras-chave: Colecionismo, História Natural, Johann Natterer, situações etnográficas, etnografia.

\section{Introdução: o naturalista como etnógrafo}

Johann Natterer (1787-1843) chegou ao Brasil junto com a comissão científica que acompanhou a Princesa Leopoldina na ocasião do seu casamento com D. Pedro I. Nessa mesma comitiva, vieram 14 outros integrantes, cada um com cargos e funções definidas: Johann C. Mikan, na 
chefia; Emanuel Pohl, Carl Philipp F. von Martius ${ }^{1}$ e Giuseppe Raddi, responsáveis pela botânica; Johann Buchberge, no cargo de pintor de plantas; Thomas Ender, para pintura de paisagens; Ruchus Schüch, para o cargo de mineralogista; Johann B. von Spix, para zoologia; Joseph Raddi, como naturalista; Joseph Schücht foi incorporado somente após o retorno de Pohl como ajudante de Heinrich W. Schott, também botânico, que assumiu então a parte botânica da expedição; Dominich Sochor, como caçador e auxiliar de taxidermia de Natterer; e, G. K. Frick e Frübeck, como pintores temporários.

O projeto inicial planejado por Schreibers, chefe do Gabinete de História Natural de Viena e responsável pela comissão, estimava uma permanência de dois anos nas terras americanas e previa um deslocamento que incluía as atuais regiões do Nordeste, Sul e Centro-Oeste do Brasil. Os membros da comissão receberam instruções claras sobre o que deveriam observar, coletar e enviar para Viena. Compunham o conjunto de orientações as "Instruções de serviço", escritas por Schreibers; e a lista de itens, solicitada por Humboldt e Blumenbach. A esta última interessava dados estatísticos e antropológicos sobre a população autóctone do Brasil, o envio de insetos, rochas e livros brasileiros para a biblioteca da Universidade de Göttingen, além de crânios indígenas e de animais conservados em álcool para o estudo do cérebro. Mencionava ainda seu interesse por petrificações, especialmente amonitas e belemnitas; e, por ouro 24 quilates (RiedlDorn, 1999, p. 26). Enquanto que as orientações direcionadas por Schreibers tinham propósito mais operacional, sua contribuição, segundo Vanzolini, residia na realização dos procedimentos de identificação e registro das coleções. As sugestões versavam sobre a colocação de etiquetas individuais e registro do local de sua coleta, além da anotação de dados complementares perdidos após a dissecação dos animais, a exemplo da cor da íris e das partes moles (Vanzolini, 1996, p. 200).

Além dos aspectos científicos, constavam entre os objetivos delimitados elementos político-comerciais como a identificação de produtos passíveis de comercialização com o Império Austro-Húngaro.Tanto a comissão quanto o casamento de Leopoldina e D. Pedro I fizeram parte de um projeto mais amplo de articulação geopolítica europeia conduzidos por Metternich em meio ao Congresso deViena de 1815. Foi nessa ocasião que se definiu a aliança política entre a casa dos Braganças e dos Habsburgos para o fortalecimento da dinastia portuguesa na Europa e no Novo Mundo. Metternich temia o avanço dos levantes republicanos que haviam acometido a América hispânica e a Europa. A comissão científica austríaca, neste contexto, foi uma ação dentre outras de aproximação entre os dois continentes que visava prioritariamente o fortalecimento dos regimes monárquicos nos dois mundos.

Ao chegar ao Rio de Janeiro, em 1817, a comissão logo se defrontou com outros elementos que delimitaram as suas realizações. A ideia inicial de dois anos, por exemplo,

1 Vários autores tendem a tratar a expedição de Spix e Martius de modo isolado em relação à Comissão Austríaca. Todavia, como eles vieram na comitiva, estavam submetidos às ordens de permanência e retorno dos mesmos supervisores e são tratados pela bibliografia geral da Comissão Austríaca como seus integrantes, decidi seguir essa última orientação. 
se mostrou impossível diante das condições impostas pelo clima político no Vice-reino, pelas condições de deslocamento, pelos recursos econômicos disponíveis, dentre outros fatores. Os primeiros a retornarem, Johann Mikan, Thomas Ender, Johann Buchberger e Giuseppe Raddi, o fizeram logo em 1818. E a segunda grande parte dos integrantes da comissão permaneceu no Brasil até 1821, quando ela foi oficialmente dissolvida. A incerteza política do ano precedente à Independência do Brasil junto com a experiência anterior de 1789 na Europa fazia parecer possível um levante revolucionário e, por segurança, todos os membros da comissão voltaram, exceto Johann Natterer e Dominich Sochor.

Natterer, cujo sonho sempre foi alcançar as terras do Mato Grosso, abdicou das questões de segurança e conseguiu driblar as ordens de retorno à Europa em 1821. Junto com o seu caçador, Sochor, seguiu rumo ao coração do Brasil numa longuíssima travessia que durou mais 14 anos. Durante o período em que esteve no Brasil, Natterer dedicou todo o seu trabalho à formação e à ampliação das coleções de história natural de Viena, sendo reconhecido por seus contemporâneos como o príncipe dos colecionadores (Riedl-Dorn, 1999), numa referência aos seus esforços e capacidade produtiva.

Apesar da distinção que o título pode sugerir, Natterer advinha de uma família humilde. Seu pai, negociante de coleções de animais empalhados, ascendeu socialmente a partir dos primeiros esforços de institucionalização da História Natural. Francisco I, Imperador Austro-Húngaro, desejoso de montar um gabinete, adquiriu em 1794 de Joseph Natterer Sênior as coleções iniciais e o nomeou seu guardião (Riedl-Dorn, 1999, p. 13). Seus dois filhos, Joseph e Johann Natterer, na época com 8 e 7 anos respectivamente, cresceram nesse ambiente sendo treinados pelo pai nas técnicas de caça e empalhamento e tendo a possibilidade de exercitar suas habilidades a serviço do gabinete. Após a ascensão de Schreibers à direção do gabinete de História Natural, em 1806, Joseph Natterer Sênior foi contratado como primeiro assistente. A ordem hierárquica (de idade e formação) era clara e Joseph Natterer filho foi primeiramente incorporado aos quadros técnicos do Gabinete. Johann realizava serviços esporádicos, como a transferência das coleções durante o período da invasão napoleônica (a fim de evitar os saques franceses) e a formação de pequenas coleções nos arredores de Viena e ao Norte da Itália. ${ }^{2}$

Quando o casamento imperial foi estabelecido e com ele o envio de uma comissão científica tornou-se factível, Johann Natterer já dispunha de um elevado prestígio junto a Schereibers e ele o indicou ao cargo de chefe da expedição. A ausência de uma formação superior fez com que Natterer fosse preterido ao cargo em favor de Mikan, professor catedrático de História Natural da Universidade de Praga, indicado pelo médico do Imperador, von Stiff. É interessante observar que nessa ocasião tornou-se explícita a proeminência da formação em relação à experiência. Contudo, o estabelecimento de planos de pesquisa independentes e a equiparação dos vencimentos de Natterer aos de

2 Os modos de atuação da geração na construção das possibilidades econômicas no interior das sociedades e famílias não é novidade na literatura sociológica. Elias (1997) e Sayad (1998) apresentam bons exemplos de como ela se processa em contextos distintos. 
Pohl, botânico responsável pela exposição, com formação em medicina e substituto de Mikan nas aulas de História Natural na Universidade de Praga, nos desvela os limites desse campo ainda em processo de institucionalização. Parece claro que as hierarquias já começavam a ser delineadas enquanto a organização das instituições ainda estava em processo. ${ }^{3}$

No retorno de Natterer a Europa, em 1835, um cenário bastante diferente estava estabelecido. Durante os anos em que esteve no Brasil, havia ocorrido justamente a fase mais explosiva dos conhecimentos de avifaunas, sua área de maior domínio (Vanzolini, 1996, p. 215). A História Natural já havia sido institucionalizada, havia um mercado de compra e venda de coleções, uma rede significativa de museus europeus e a disciplina era lecionada nas universidades. Apesar da consolidação da disciplina e das instituições na Europa que poderiam favorecer o naturalista, Natterer reencontra o Império AustroHúngaro em claro declínio. O Museu Brasileiro em Viena (1821-1836), principal destinatário das coleções enviadas, fechou justo no ano seguinte ao seu retorno e o levou a ser readmitido no Gabinete de História Natural em condições semelhantes às deixadas quando da sua partida para o Brasil.

A sua morte, em 1843, em decorrência de uma hemorragia cerebral, pôs fim ao seu trabalho ainda inconcluso quando tentava realizar seu último e mais grandioso projeto, uma grande obra síntese da ornitologia brasileira. Dos trabalhos escritos publicados, temse notícia de apenas dois. Um em colaboração com Fitzinger sobre os jacarés brasileiros, ricamente ilustrado e com a distribuição geográfica indicada, e outro sobre Pirambola brasileira (Vanzolini, 1996, p. 216). Pelzeln foi o responsável por avançar nos estudos sobre as coleções de aves e mamíferos enviadas por Natterer e garantir alguma visibilidade para o naturalista nas décadas seguintes.

Apesar dessas e de outras dificuldades, Natterer formou uma das coleções que hoje contabilizam, a despeito de todas as perdas, 64.689 animais, 43.700 plantas e 2.445 objetos indígenas (Feest, 2014). Desses itens, destaca-se ainda hoje a importância das coleções etnográficas depositada no Weltmuseum de Viena. Ela constitui uma das mais representativa das populações indígenas brasileiras do século XIX e surpreende até hoje pela beleza e diversidade, há objetos referidos a aproximadamente 80 povos (Feest, 2014). Além da importância das suas coleções etnográficas (Feest, 2014, 2012; Augustat, 2014; Schloutauer, 2014; Thompson, 2011), suas listas de vocabulários indígenas continuam sendo importantes fontes de informações e conhecimento sobre os povos autóctones (Adelaar, 2014). Foi, inclusive, a partir desses dois conjuntos de materiais, objetos etnográficos e listas de vocabulários que as contribuições de Natterer para o campo científico, obliteradas por quase 150 anos, ${ }^{4}$ foram retomadas.

3 Para a análise das oposições e hierarquias entre o gabinete e o campo e sua consolidação em meados do século XIX, ver Bleichmar (2009).

4 Para uma genealogia mais ampla da redescoberta do material de Johann Natterer pelo campo científico, ver Santos (2016). 
A dimensão, portanto, das relações entre História Natural e dados etnográficos coloca-se como ponto fundamental desse debate. No começo do século XIX a etnografia como prática era bastante distante do que preconiza os manuais etnográficos atuais. Os preceitos do trabalho de campo e da observação participante (Malinowski, 1976) nem de longe haviam sido pensados, tampouco as orientações da Antropologia Social haviam sido estabelecidas (Evans-Pritchard, 1975). A distância entre o que hoje se faz na Antropologia e o que se fazia há duzentos anos pode parecer ao leitor um abismo intransponível. Contudo, muito se tem dito sobre a influência dos primeiros viajantes na formulação do enquadramento moral da Antropologia Contemporânea. Clifford (1988) chega mesmo a sugerir a constituição de um campo semântico afetivo desenvolvido naquele período, que é legado ao século XX; Oliveira (1987) aponta para a utilização dos materiais recolhidos e dos dados produzidos pelos viajantes como a base sobre a qual os primeiros antropólogos, como Mauss e Durkheim, utilizaram para conformação da teoria antropológica moderna; e Jamin (1978) apresenta como o surgimento de uma determinada forma de alteridade, posteriormente denominada de antropológica, que esteve imbricada com a atuação dos pesquisadores vinculados à Sociedade dos Observadores do Homem (1799-1805).A partir de perspectivas teóricas e contextos muito distintos, essas referências estão nos dizendo duas coisas. A primeira que, no âmbito do estudo dos naturalistas-viajantes, é fundamental conectar áreas disciplinares e realizar um trabalho transdisciplinar. E a segunda, que há conexões entre a produção do universo dos naturalistas-viajantes e os modos de produção de conhecimento da Antropologia Contemporânea, mais particularmente no que diz respeito aos modos de produção da etnografia e das coleções.

As coleções, a semelhança da autoria (Foucault, 1969), recebem quase sempre apenas uma indexação - o nome do colecionador. Contudo, quando analisamos os contextos de sua produção é possível perceber que elas contam com a participação fundamental e indispensável das redes locais que auxiliam o naturalista e que são determinantes para os tipos de objetos recolhidos. Dito de outro modo, elas operam diretamente na produção do colecionismo.

Quando analisamos o conjunto de interlocutores e coprodutores de Johann Natterer, verificamos a existência de pessoas oriundas de várias origens e com atuações diversas. Escravos, indígenas, tenentes, milicianos, governadores de província, comerciantes, agentes de câmbio, uma infinidade de pessoas indispensáveis as suas viagens e a sua produção científica. As realizações de um naturalista, portanto, dizem respeito não apenas ao indivíduo, mas à multiplicidade de pessoas localizadas em contextos políticos e sociais estratégicos. A formação dessa rede de coprodutores das coleções pode ser entendida, tal como formulado por Oliveira (2015), como situações etnográficas. ${ }^{5}$ Para o autor, a pesquisa

Segundo o autor, a "noção de 'situação etnográfica' se reporta ao conjunto de relações que o pesquisador, contemporaneamente à pesquisa, mantém com todos os atores sociais que de algum modo intervêm no campo. A minha intenção ao propor a noção de 'situação etnográfica' é estimular o investigador a descrever a sua pesquisa como um sistema de relações sociais, não como um relato de incidentes de viagem nem como o aprofundamento de experiências individuais." (Oliveira, 2015, p. 43). 
não pode ser entendida como algo da ordem individual, se não e apenas por meio das relações estabelecidas em campo. Desse modo, a compreensão da experiência perpassa necessariamente o entendimento da rede envolvida na produção dos dados. Nesse sentido, para a análise desse artigo, descreveremos as situações etnográficas relativas à produção de três grandes conjuntos de coleções: os crânios indígenas, as listas de vocabulário e os artefatos etnográficos. Penso que ao analisar o colecionismo empreendido no âmbito da História Natural da primeira metade do século XIX a partir da noção de situações etnográficas construímos novas possibilidades de compreensão e entendimento desses objetos, corpos e vocabulários não apenas como itens exóticos e externos, mas como elementos intrínsecos e fundamentais ao processo de conquista e de formação dos Estados Nacionais.

\section{Situações etnográficas e colecionismo}

\subsection{Em busca dos crânios para Blumenbach}

No ano seguinte à chegada de Natterer a Cuiabá/MT, temos notícias de um incidente provocado por Natterer ao tentar obter um crânio indígena. O colecionismo de crânios nesse período não era uma tarefa fácil e era comum recorrer aos corpos em hospitais e cemitérios. Neuwied, por exemplo, conseguiu alguns dos seus exemplares por meio de escavações em cemitérios indígenas (Domingues, 1995, p. 50). O crânio por ele obtido foi enviado diretamente para Blumenbach, que realizou a sua descrição. O próprio Neuwied antecipava os efeitos que o uso contínuo do batoque, característico dessas populações, provocava na conformação óssea do crânio, levando à queda dos incisivos inferiores e à deformação da mandíbula (Wied, 1958, p. 287). Buscava o naturalista compreender os usos desses adornos tanto por meio do seu significado local, a que dedicou longas descrições, como à comparação com usos semelhantes entre outras populações. Identificava proximidade com Charruas, descritos por Azzarra e os povos das índias ocidentais e do Oceano Pacífico a partir dos trabalhos de Blumenbach ${ }^{6}$ e Cook. ${ }^{7}$

Baldus (1969) indicou que o crânio remetido por Neuwied à Europa foi o primeiro referido aos Botocudos, tornando-se referência para os estudos de craniometria não

6 BLUMENBACH, Frid. De generis humanae varietate nativa. Gottingae:Vandenhoek et Ruprecht, 1975.

7 COOK, James. Última viagem à volta ao mundo. Journal of captain Cook's last voyage to the Pacific Ocean, and in quest of a North-West Passage, Between Asia \& America, performed in the years 1776, 1777, 1778 and 1779. Hartford: Nathaniel Patten, 1783. v. I, Pl II. 
somente de Blumenbach, como de Morton $^{8}$ e de Ehrenreich. ${ }^{9}$ À época, a conformação do maxilar chegou a ser questionada quando Hartt $^{10}$ encaminhou um crânio botocudo a Jeffries Wyman para estudo. As diferenças na proeminência do maxilar inferior levaram à controvérsia definida favoravelmente por Ehrenreich ao crânio de Wied (Baldus, 1969). O interesse dos dois naturalistas relacionava-se às instruções de Blumenbach, que almejava realizar estudos de antropologia com os crânios.

O mais dedicado coprodutor de coleções de crânio para Johann Natterer em Cuiabá foi Antônio Patrício Manso, cuja relação foi iniciada a partir da sua chegada em Cuiabá em 1824. Filho de um pintor, Antônio Manso nasceu em 1790 em São Paulo. Aos 22 anos havia se estabelecido em Campinas, onde, à semelhança do pai exercia o mesmo oficio (Mendonça, 2005, p. 17). Por meios não indicados, ele conseguiu formar-se em medicina pela Universidade de Coimbra (Ramirez, 1968, p. 142) e em seguida foi aprovado para o cargo de cirurgião-mor da província do Mato Grosso, onde passou a exercer a profissão a partir de 1822 (Melo Leitão, 1937, p. 202).

Ao saber da morte de um indígena no hospital administrado por Manso, Natterer solicita que lhe corte a cabeça e lhe entregue o crânio ao que prontamente o médico atende. Ao tentar obter os crânios diretamente dos corpos recém-falecidos, ao contrário dos cemitérios como havia feito Neuwied, Manso despertou a suspeita e a indignação da população local que levou o caso ao Juiz local devido ao fato do indígena ser cristão. Diante da aclamação pública, o Juiz de Fora, Antônio José da Veiga, ordenou o sepultamento do crânio ${ }^{11}$ alegando o caráter antimoral implicado na ação de cortar a cabeça de um indígena e retirar-lhe o crânio. Na ocasião, recorreu-se ao batismo como elemento para contenção da prática científica empreendida por Natterer e Manso.

Em outubro de 1828, Natterer realiza uma segunda tentativa de obter um crânio indígena. Nesta ocasião escreveu a José Gomez da Silva, comandante de uma bandeira contra os Cabixis, na tentativa de obter um crânio e os seus objetos. Recomendava ao comandante cortar a cabeça de um ou dois homens já feitos, retirar os miolos, sem alterar o crânio e secá-los próximo ao fogo para não apodrecerem. Pedia ainda que recolhessem os trastes dos indígenas, tanto dos homens quanto das mulheres para o fim de formar

8 Samuel George Morton (1799-1851) naturalista norte-americano autor da obra Crania Americana (Baldus, 1969).

9 Paul Max Alexander Ehrenreich (1855-1914) formado em medicina e filosofia empreendeu pesquisas no Egito e na Índia, contudo, seus trabalhos mais relevantes e conhecidos foram desenvolvidos no Brasil onde viajou pelas províncias do Espírito Santo, entre os anos de 1884 e 1885, e pela Amazônia, para onde foi em 1887. Em 1888 realizou a sua segunda expedição à Amazônia (Schaden, 1964).

10 Charles Frederick Hartt (1840-1878) geólogo canadense integrou a comissão científica de Agassiz ao Brasil e onde integrou, durante os anos de 1875 e 1877, a Comissão Geológica do Império do Brasil constituída por D. Pedro II entre 1875 e 1878 (Sanjad, 2004)

11 Registro de Correspondência da Presidência da Província às Autoridades Provinciais, período de 1829-1831, estante 05, n. 05, p. 152, v. 153. Arquivo Público do Estado do Mato Grosso. 
coleções para o Imperador da Áustria. Prometia recompensar-lhes financeiramente. ${ }^{12}$ Nesta tentativa, Natterer também não foi bem sucedido. Mesmo longe dos olhares vigilantes dos habitantes da vila, em meio ao conflito já estabelecido, o comandante negou-se a atender ao pedido do naturalista.

A terceira tentativa de obtenção do crânio diz respeito a negociações travadas com os indígenas Guamás, integrantes da tropa do Capitão Albuquerque e conhecidos por Natterer durante sua estadia na cidade de Cuiabá. A tropa do capitão, adentrando os sertões de Cuiabá havia se deparado com um grupo de indígenas "selvagens”. Enquanto os homens haviam saído para caçar, as mulheres e as crianças cuidavam das moradias quando foram levadas pela tropa do capitão. Dali a alguns dias, os homens retornaram e atacaram a tropa em represália à primeira ação de sequestro das mulheres e crianças do grupo. Nesse confronto, deixaram vários objetos e um dos indígenas "selvagens" morreu. O naturalista que seguia suas incursões acompanhando as tropas coloniais, fez o capitão lhe prometer a entrega dos arcos e das flechas. Contudo, não lhes entregou nada e Natterer obteve os objetos por meio dos indígenas Guamás, aos quais também solicitou o crânio do outro indígena morto. Os Guamás entregaram parte dos objetos, mas não o crânio, tornando a terceira tentativa de obtenção do item também frustada. ${ }^{13}$

Por fim, na quarta e última tentativa, Natterer obteve o crânio por meio do Tenentecoronel Jeronymo Joaquim Nunes, comandante da cidade de Cuiabá. Pelas anotações de Natterer, que acompanharam o envio do item, podemos acessar o seu contexto de obtenção:

Crânio de um índio Schamucoco [Chamacoco]. Essa nação mora abaixo de Coimbra, na província do Chaco, e é severamente perseguida pelos guaicurús e escravizada por eles. Este, do qual é o crânio, tinha cerca de 20 anos de idade e morreu aqui, no hospital local [em Cuiabá]. Ele pertencia ao comandante da cidade, tenente-coronel Jeronymo Joaquim Nunes, que o recebeu de presente dos Schamucocos quando era comandante do Forte Coimbra, em uma oportunidade em que estes buscaram proteção junto a ele. (Heger, 1882 apud Feest, 2012a, p. 26).

As correspondências de Natterer com o Tenente Joaquim Nunes estão datadas no ano de 1828, o que nos leva a acreditar, assim como Feest (2012b), que foi mais ou menos nesse período que o naturalista finalmente conseguiu obter o crânio.À diferença das outras tentativas, nessa ocasião exitosa, o naturalista recorreu diretamente à autoridade máxima da cidade. O crânio havia sido presenteado ao tenente por indígenas estrangeiros em meio ao processo de pacificação desses. O conjunto das marcas - posição administrativa combinada com indígenas estrangeiros não pacificados - parece ter funcionado como o elemento central para a obtenção do crânio pelo naturalista.

12 Carta a José Gomez da Silva, 17/10/1828, MVK Natterer, 27/3-4.

13 Carta a Mareschal, 16/06/1826, MVK Natterer 19/4-8, 22/ 1-2. 


\subsection{Idiomas cativos e femininos}

Natterer buscava registrar os vocabulários indígenas, seus costumes, os modos como utilizavam determinados objetos como meios para estabelecer as diferenças fundamentais entre os segmentos humanos. O homem, segundo os critérios da História Natural da primeira metade do XIX, participava do grupo zoológico e suas classificações raciais não estavam estabelecidas hierarquicamente, elas indicavam apenas as diferenças dos tipos biológicos. Foram os trabalhos de Buffon e Cuvier que abriram caminhos para a formulação do conceito de raça em termos hierárquicos ao propor a busca das leis da natureza para explicar as diferenças culturais. Suas pressuposições acerca do papel desempenhado pelos aspectos físicos nas características mentais e culturais levou à passagem da diferença para desigualdade. A raça como hierarquia e a Antropologia Física como disciplina privilegiada do seu estudo somente pode ser observada nos manuais da disciplina a partir da segunda metade do século XIX (Seyferth, 1993, p. 175). Os vocabulários funcionavam, assim, como um elemento importante para a caracterização dos povos, sem contudo estabelecer hierarquias entre eles.

Se a busca por crânios indígenas esteve majoritariamente relacionada ao universo masculino, a produção das listas de vocabulário, ao seu inverso, esteve em sua maioria relacionada às mulheres cativas. Dos contatos descritos pelo naturalista, temos notícia que o primeiro registro foi realizado ainda durante a existência da comissão austríaca, quando, deslocando-se para o Sul do Brasil, hospedou-se na casa do Juiz de Curitiba e conheceu Rufina, indígena de sua propriedade. Com ela produziu uma lista de vocabulário que identificou como correspondente à registrada por Eschwege em seu jornal. ${ }^{14} \mathrm{~A}$ referência à obra de Eschwege possivelmente corresponde ao Journal von Brasilien, publicado em 1818. A partir desse momento, Natterer passou a registrar as listas de vocabulários dos demais povos indígenas que encontrou, formando assim, uma significativa coleção de vocabulários ao longo do tempo (Adeelar, 2014).

Um segundo momento de produção das listas de vocabulário se deu na apreensão de um grupo de mulheres e crianças Bororo que foram levadas como prisioneiras para a fazenda do Coronel João Pereira Leite. Nesta ocasião, ele aproveitou e entrevistou o grupo, produzindo uma lista de vocabulários indígenas. Já em Jacobina, na casa do mesmo Coronel, ele entrevistou uma menina de 15 anos com quem pôde ampliar sua lista (Feest, 2012 b, p. 82). Ao final, Natterer mencionou ter conseguido listar as palavras indígenas já identificadas por Eschwege e alguns outros objetos que não especificou em detalhes. ${ }^{15}$ Apesar da modéstia com que trata a lista produzida - igualando-a à produção de seu contemporâneo Eschwege -, a lista de Natterer possuía outras virtudes. Ao apresentar o contexto de produção de dados, segundo Feest (2012b), suas listas permitiam demonstrar

14 Carta a Schreibers, 02/03/1821, MVK Natterer 4/1-8, 5/1-4.

15 Carta a Mareschal, 16/06/1826, MVK Natterer 19/4-8, 22/ 1-2. 
que a divisão entre Bororos "Orientais" e Bororos "Ocidentais" correspondiam a mera divisão geográfica e não a uma divisão linguística ou cultural (p. 83).

O apoio do Coronel Pereira Leite não foi fortuito ou passageiro, Natterer se hospedou por meses em sua fazenda, perto da cidade de Cárceres. Ali pôde testemunhar o longo processo de pacificação e aprisionamento das mulheres e crianças indígenas, bem como as tentativas de sua recuperação pelos homens indígenas. Foi também nesse contexto que ele empreendeu algumas das suas tentativas de obtenção dos crânios indígenas relatados no tópico anterior. Deve-se observar a divisão sistemática na produção do colecionismo empreendido pelo naturalista: os objetos advindos do conflito e da guerra eram negociados por meio e com os homens; os itens que necessitavam de diálogo e explicação eram obtidos por meio das mulheres submetidas ao processo de dominação e controle colonial.

\subsection{Objetos de pacificação}

Dentre os principais interlocutores de Natterer na formação das coleções etnográficas, destaca-se Peixoto de Azevedo. Conhecido em 1823, enquanto desbravava o Paraná, Peixoto de Azevedo havia auxiliado Natterer num período em que o naturalista andava bem doente. Além de auxílios médicos, Peixoto de Azevedo auxiliava o naturalista com o empréstimo de indígenas para o trabalho com o naturalista e com informações técnicas sobre a região. O tenente havia sido designado desde 1819 tenente de milícias, encarregado de desbravar o Rio Paranatinga. Partiu acompanhado de 50 soldados milicianos que percorreram as regiões do Mato Grosso, Xingu, desembocando no Pará. O capitão-geral Magessi, que o havia designado, buscava alternativas para o escoamento dos produtos do Mato Grosso para o porto de Belém pelas vias fluviais (Mendonça, 2005). Na expedição que durou aproximadamente dez anos, Peixoto de Azevedo tornou-se um importante conhecedor da região e um valioso aliado para Natterer. Natterer tendo notícias das mumificações das cabeças e sabendo que Peixoto de Azevedo andava entre os Apiacás e Mundurukus, desejava obter por intermédio do miliciano um exemplar para compor as coleções austríacas. Contudo, o que Natterer não esperava era obter ainda mais itens.

Conhecedor dos caminhos e das práticas, Peixoto de Azevedo colecionava objetos para remeter ao Museu Nacional do Rio de Janeiro. Sua aliança com os Apiacás era de longa data e se tem notícias da remessa de seus objetos para o Museu Real até $1827 .{ }^{16}$ Além disso, Peixoto de Azevedo era considerado um homem estratégico pelo presidente da província do Mato Grosso, José Saturnino da Costa, que o utilizava não apenas para o conhecimento geográfico da região e amansamento dos indígenas, como também como fonte de informação das disputas políticas e econômicas em relação à vizinha América 
Hispânica. Por isso, lhe concedia amplo passaporte e permitia que ele utilizasse a estrutura dos fortes e das canoas do Estado. ${ }^{17}$

Por meio de Peixoto de Azevedo, Natterer passou também a conhecer a dinâmica de deslocamentos na região. Soube que a cada ano saíam expedições de Cuiabá para o Pará. Embora custosas, eram o meio mais eficaz para deixar a região; e Natterer pretendia seguir em alguma delas descendo o rio. Sobre o destino a seguir, o naturalista vacilava em seus planos. Tinha notícias naquele momento que nem o Maranhão, nem o Pará reconheciam a autoridade do imperador. Além disso, havia indícios de que o interior do Pará e do Rio Negro estavam politicamente mais estáveis e em combinação com a política imperial. Os conflitos na capitania do Piauí e na Bahia, por sua vez, tornavam incertos os planos da expedição após o Pará. ${ }^{18}$

Esse período de chegada a Cuiabá foi bem difícil para Natterer. Ele esteve por muito tempo doente. As inflamações no figado foram crescentes e o levaram a ficar muito tempo acamado com fortes complicações abdominais. ${ }^{19} \mathrm{O}$ seu processo de recuperação foi lento e durante esse período a formação de coleções somente não ficou prejudicada graças às doações de Peixoto de Azevedo. Os pássaros e os artefatos indígenas foram os mais significativos. Os fardamentos mundurucus da coleção do Weltmuseum provavelmente foram incorporados nessas doações. ${ }^{20}$ Foi por meio de Peixoto de Azevedo que Natterer conheceu a ocupação daquelas regiões pelos Mundurukus, Guanas e Guaicurus.

Os Mundurukus ocupavam a parte baixa dos Tapajós e, na época, eram muito numerosos e guerreiros, temidos pelas nações vizinhas. No momento em que Natterer passou pela região, eles estavam em paz com os brasileiros e o naturalista pretendia passar um tempo entre eles e obter algumas coleções. No entanto, considerou ser mais seguro remeter o mais breve possível as coleções formadas para Viena. Nesse período estimava enviar dez caixotes. Em sua avaliação sobre os objetos etnográficos remetidos, Natterer considerava os objetos dos Mundurukus semelhantes aos dos Apiacás, Bororos e Parecis. E, assim como os Mauhés, eles também possuíam flechas envenenadas. ${ }^{21}$ Além desses objetos, Natterer enviava na ocasião objetos dos Guanas obtidos na sua passagem pelo Forte Coimbra, onde estavam situados. Enviava ainda material dos Guatós, com os quais travou contato na foz do Rio São Lourenço. ${ }^{22}$

Peixoto de Azevedo, em sua atuação na região dos Rios Negro, Arinos, Tapajós até Santarém vinha produzindo uma coleção destinada ao Museu Nacional. Nela continham

17 Ofício de José Saturnino da Costa, presidente da província do Mato Grosso, ao Visconde de Santo Amaro, Ministro e Secretário de Estado dos Negócios Estrangeiros, 15/03/1826, Livro de Ofícios expedidos às secretarias de Estado, Estante 05, n. 13, p. 18, Arquivo Público do Estado do Mato Grosso.

18 Carta a Schreibers, 25/08/1823, MVK Natterer, 13/ 2-8, 14/ 1-5.

19 Carta a Joseph, 16/12/1824, WStLB HS Natterer 7882.

20 Carta a Joseph, 16/12/1824, WStLB HS Natterer 7882.

21 Carta a Joseph, 16/12/1824, WStLB HS Natterer 7882.

22 Carta a Joseph, 16/12/1824, WStLB HS Natterer 7882. 
objetos Apiacás e Mundurukus. Natterer disse enviá-los a Viena. Embora as condições de negociação não estivessem claras, é provável que o pesquisador tenha conseguido convencer Peixoto de Azevedo. Em uma carta de julho de 1826, Natterer o escrevia comprometendo-se a enviar materiais para o Museu Real se ele cedesse suas coleções. Para o austríaco, no Museu do Rio de Janeiro "vale-se o número do que manda, porque lá não conhecem nem sabem estimar as qualidades". Na remessa seguinte, Natterer informava ao seus superiores remeter dos Apiacás um diadema de propriedade de um dos caciques; dos Bororos, uma coifa de dentes e garras de onça e uma faca que é um dente de Capivara. Na mesma carta, avaliava Peixoto de Azevedo como um homem ativo, curioso e com algum conhecimento. ${ }^{23}$

As relações de Peixoto de Azevedo com as populações indígenas eram bastante próximas e ele empenhava-se em manter essas amizades. $\mathrm{Na}$ ocasião de sua viagem à cidade de Assunção, no Paraguai, anteriormente mencionada, um incidente colocou-o em apuros. Ao chegar ao Forte Olympio, no caminho daquela capital, o comandante pediu a Peixoto de Azevedo que persuadisse o chefe indígena dos Aycurus, Calapá, a entrar no forte para o recebimento de presentes e brindes. Azevedo convencido das boas intenções do comandante, procedeu ao pedido e bastou que Calapá cruzasse a muralha para que trinta soldados o rendessem e a sua comitiva. Rendidos, os indígenas foram presos. A reação de Peixoto de Azevedo frente à traição dupla do comandante do Forte expressa bem os mecanismos necessários para a manutenção da ordem naquela região nas primeiras décadas do século XIX.

Temendo uma represália dos indígenas, que poderiam voltar-se não apenas contra os comandantes paraguaios, mas também às fortificações do Mato Grosso, Peixoto de Azevedo argumentava que:

perigava a sua vida, e a de toda tripulação e até mesmo que podendo os índios supor que ele Peixoto tivesse algumas instruções do governo do Mato Grosso para obrar daquele modo, poderiam os índios fazer incursões nos habitantes da nossa fronteira para vingarem a traição feita a seu chefe; mas tudo foi ---; porque o índio continuou a ficar preso, e só não lhe responderam com lugares com nuns estratagemas de guerra dizendo estimarem aquela ocasião de se apoderarem do Calapá que lhes tinha feito grandes hostilidades. ${ }^{24}$

Peixoto finalmente consegue intermediar a liberação de Calapá e o escolta para longe do forte. Ao longo do caminho tentou convencer-lhe da sua não participação no ato e chegou mesmo a dizer que também foi traído. Como modo de compensação entregou-lhes os brindes que levava consigo e, ao final, conseguiu convencer o indígena

23 MVK Natterer, sem referências adicionais. Publicada Wiener Zeitschrift für Kunst, Literatur, Theater und Mode, Nr. 115, 24. September 1825, 957-959.

24 Ofício de José Saturnino da Costa, presidente da província do Mato Grosso, a Visconde de Inhanbupu (Antônio Luís Pereira da Cunha), Ministro dos Negócios Estrangeiros, 15/06/1826, Livro de ofícios expedidos às secretarias de estado, estante 05, n. 13, p. 27, Arquivo Público do Estado do Mato Grosso. 
de sua boa fé. Mas, não sem razão, o presidente da província escrevia ao Imperador solicitando que intermediasse junto aos comandantes da fronteira do Paraguai a proibição da venda de armas e munições para os indígenas Bayaz e Aycurus. ${ }^{25}$

Natterer seguia utilizando sua rede de contatos para obter as informações necessárias ao avanço da sua expedição. Em carta a Peixoto de Azevedo, em novembro de 1825, demandava dele notícias sobre a sua última viagem. Por intermédio do filho do presidente da província, Sr. Fleury, soube que ele havia conseguido mais alguns objetos dos apiacás e quase 400 pássaros. Imaginava certo exagero do Sr. Fleury, estimava que Peixoto de Azevedo houvesse conseguido no máximo a metade e pedia-lhe que enviasse mais notícias. Natterer ansiava por formar uma coleção de pássaros e quadrúpedes, além de mais objetos indígenas e se propunha a descer o Rio Arinos na companhia do tenente de milícias. ${ }^{26}$

A chegada ao Mato Grosso, apesar de muito almejada, obrigou Natterer a realizar algumas paradas estratégicas. Escolheu demorar-se emVila Maria em virtude da carestia e escassez de mantimentos em Mato Grosso. Além disso, considerava que o clima do local, mais sadio, o ajudasse a pôr fim às moléstias de que sempre padecia. Durante essa estadia, despojou os Bororos dos melhores objetos que eles tinham, embora avaliasse suas flechas como muito compridas e mal feitas. Ainda por meio do Sr. Fleury soube da presença, no diamantino, de Parecis ou Cabexis, de cabelos longos, e que vendiam por lá balaio e peneiras. Sugeriu a Peixoto de Azevedo que se apanhassem algumas coisas deles, em caso de reaparecerem. ${ }^{27} \mathrm{~A}$ aquisição de peças era um dos modos de obtenção das coleções etnográficas e o uso de intermediários como Peixoto de Azevedo foi estratégico para Natterer.

\section{Considerações finais: o colecionismo no âmbito da História Natural}

O colecionismo resultante das práticas empreendidas no âmbito da História Natural apresentava regras de funcionamento e ordens morais próprias e independentes das estabelecidas para aquele campo de conhecimento. Alguns elementos aparecem como centrais nessa articulação. $\mathrm{O}$ aspecto da concorrência entre os naturalistas recebia no colecionismo o grande palco para sua exibição.A raridade e a quantidade de novas espécies obtidas eram os critérios mais recorrentes na avaliação mútua das coleções. E, a fim de alcançá-los, os naturalistas se utilizavam dos expedientes mais diversos. As compras eram frequentes e realizadas entre naturalistas. Além disso, recorriam a pessoas sem formação específica, como fazendeiros, colonos, populações indígenas. Nesses casos, cabia ainda ao

25 Ofício de José Saturnino da Costa, presidente da província do Mato Grosso, a Sua Majestade Imperial, 09/08/1826, Livro de ofícios expedidos às secretarias de estado, estante 05, n. 13, p. 33v, Arquivo Público do Estado do Mato Grosso.

26 Carta a Peixoto de Azevedo, Nov-Dez, 1825, MVK Natterer, 20/3-5.

27 Carta a Peixoto de Azevedo, 24/03/1826, MVK Natterer, 20/5-8. 
naturalista ensinar as técnicas adequadas de obtenção e armazenagem. As permutas entre cientistas eram ainda outro meio corriqueiro de obtenção. ${ }^{28}$

Demonstrar a formação dessa rede e sua participação na produção das coleções desmontando a ideia de um único colecionador por meio da explicitação das situações etnográficas foi o principal objetivo desse artigo. Como segundo plano, buscamos demonstrar as relações existentes entre a expressão geopolítica territorial aliada à dimensão científica propriamente dita. Nesse sentido, aparecem as disputas territoriais, os processos de pacificação dos indígenas, os aprisionamentos das mulheres - situações em que o colecionismo ia produzindo sua materialidade. Ainda no colecionismo dos vocabulários e itens indígenas, os naturalistas tomaram diferentes posições morais, muitas vezes concordando e concorrendo para afirmação da ordem colonial estabelecida. Natterer assim compilou os vocabulários indígenas entre os Bororos aproveitando-se do aprisionamento de um grupo de mulheres e crianças e também nas tentativas de obtenção dos crânios indígenas por meio de grupos rivais. A ação do Juiz em repreendê-lo demonstra os limites morais da época e a posição social ocupada pelos indígenas cristãos ao contrário dos grupos não pacificados e estrangeiros aos quais era possível aceitar suas cabeças e destiná-las aos museus.

Apesar dessas considerações, as coleções formadas sobre as populações indígenas brasileiras constituem a grande preciosidade dos legados da comissão científica austríaca (Feest, 2012b). Cuvier, em seu relatório sobre os acréscimos ao Gabinete de História Natural, alertava que dentre os objetos e espécimes a serem apresentados não deveríamos focar apenas nos que são raros, preciosos ou aos que saltam aos olhos pelo seu brilho. Pois, "o menos vistoso dos produtos que desprezamos pode estar destinado a mudar a face do mundo ou o destino da humanidade". ${ }^{29}$ As coleções etnográficas, itens de segunda classe no colecionismo do início do século XIX, passam hoje por um período de intensos debates sobre os seus significados e sentidos. Ainda não sabemos se estão destinadas a "mudar a face do mundo", mas, certamente, a sua retomada pelas populações que foram exploradas por quase dois séculos vem indicar uma mudança em seu mundo. A realização de trabalhos que permitem a compreensão de sua formação no interior dos sistemas mais amplos que lhe deram causa abre caminhos para essas novas releituras. Espero que de algum modo esse trabalho venha a contribuir para além dos debates da Antropologia: aos usos políticos do legado das populações indígenas.

\section{Referências}

ADELAAR, Willem F. H.; BRIJNEN, Hélène B. Johann Natterer's Linguistic Heritage. In: Archiv für Völkerkunde 63-64.Viena: Lit Verlag, 2014. p. 163-175.

28 Para uma análise detida desses aspectos, ver Santos (2016).

29 "Rapport sur les agrandissements dont le cabinet d'Histoire naturelle a besoin" (Kury apud Camenietzki, 1997, p. 67). 
AUGUSTAT, Claudia. In the Shadow of Johann Natterer. Johann Emanuel Pohl's Ethnographic Collection. In: Archiv für Völkerkunde 63-64.Viena: Lit Verlag, 2014. p. 97-108.

BALDUS, Hebert. Maximiliano, Príncipe de Wied-Neuwied e o Estudo dos Índios no Brasil. In: WIED, Maximiliano Neuwied. Viagem ao Brasil: 1815-1817. São Paulo: Melhoramentos, 1969. p. 101-108.

BAUDRILLARD, Jean. O sistema dos objetos. Trad. Zulmira Ribeiro Tavares. São Paulo: Perspectiva, 2000.

BLEICHMAR, Daniela.Visible empire: scientific expeditions and visual culture in the Hispanic enlightenment. Postcolonial Studies, v. 12, n. 4, p. 441-466, 2009.

CAMENIETZKI, Carlos Ziller. Ordem e Natureza: coleções e cultura científica na Europa Moderna. Anais do Museu Histórico Nacional, v. 29, p. 57-85, 1997.

CLIFFORD, James. The predicament of culture: twentieth-century ethnography, literature, and art. Cambridge, Mass: Harvard University Press, 1988.

DOMINGUES, Heloisa Maria Bertol. Ciência, um caso de política:As relações entre ciências naturais e a agricultura no Brasil Império. 1995. 321 f.Tese (Doutorado em História) - Faculdade de Filosofia Letras e Ciências Humanas, Universidade de São Paulo, São Paulo, 1995.

ELIAS, Nobert. Os alemães: a luta pelo poder e a evolução do habitus nos século XIX e XX. Rio de Janeiro: Zahar, 1997.

O Processo Civilizador: Uma história dos costumes. Rio de Janeiro: Jorge Zahar Editora Ltda., 1990.

EVANS-PRITICHARD, Edward Evan. [1964] Antropologia Social. In: ZALUAR, Alba. Desvendando Máscaras Sociais. Rio de Janeiro: Livraria Francisco Alves, 1975. p. 223-244.

FEEST, Christian. Bororo. “A Joia da coroa para a antropologia”. In:AUGUSTAT, Claudia (Org.). Além do Brasil: catálogo da exposição do Museum fürVölkerkunde.Viena, 2012b. p. 81-89.

.Johann Natterer e as coleções etnográficas dos naturalistas austríacos no Brasil. In: AUGUSTAT, Claudia (Org.). Além do Brasil: catálogo da exposição do Museum fürVölkerkunde.Viena, 2012a. p. 21-31.

The Ethnographic Collection of Johann Natterer and the Other Austrian Naturalists in Brazil. A Documentary History. In: Archiv für Völkerkunde 63-64.Viena: Lit Verlag, 2014. p. 61-98.

FOUCAULT, Michel. “Qu'est que c'est un autre?”, Bulletin de la Societé Française de Philosophic, ano 63, n. 3, p. 73-104,jul./set. 1969.

JAMIN, Jean. De la filiation déviée à l'oubli des origines. In: Apresentação ao libro COPANS, Jean. Aux origines de l'anthropologie française: las memoires de la Société des Observateurs de l'Homme en l'an VIII. Paris: Le Sycomore, 1978. p. 23-70.

MALINOWSKI, Bronislaw. [1922] Argonautas do Pacífico Ocidental: um relato do empreendimento e da aventura dos nativos nos arquipélagos da Nova Guiné Melanésia. São Paulo: Abril Cultural, 1976.

MELO LEITÃo, Cândido de. A Biologia no Brasil. São Paulo: Ed. Nacional, 1937.

MENDONÇA, Estevão de. [1919] Datas Mato-Grossenses. Niterói, RJ: Escola Typ. Salesiana, 2005. v. 2.

NEUWIED, Prinz Maximilian von Wied. Viagem ao Brasil. 2. ed. Trad. Edgar Süssekind de Mendonça e Flávio Poppe de Figueiredo. São Paulo: Companhia Editora Nacional, 1958.

OLIVEIRA, João Pacheco de. Elementos para uma sociologia dos viajantes. In: Sociedades indígenas e indigenismo no Brasil. Rio de Janeiro: Marco Zero, 1987. p. 84-148.

Regime tutelar e racionalismo. Política e religião em uma reserva Ticuna. Manaus: UEA Edições, 2015.

RAMIREZ, Ezekiel Stanley. As relações entre o Brasil e a Áustria. Rio de Janeiro: Civilização Brasileira, 1968.

RIEDL-DORN, Christa. (Org.). Johann Natterer e a missão austríaca. Petrópolis, RJ: Index, 1999.

SANTOS, Rita de Cássia Melo. Um naturalista e seus múltiplos: colecionismo, projeto Austríaco na América e as viagens de Johann Natterer no Brasil (1817-1835). 2016. 364 f. Tese (Doutorado em Antropologia Social) - 
Programa de Pós-Graduação em Antropologia Social, Museu Nacional, Universidade Federal do Rio de Janeiro, 2016.

SANJAD, Nelson. Charles Frederick Hartt e a institucionalização das ciências naturais no Brasil. História, Ciências, Saúde - Manguinhos, Rio de Janeiro, v. 11, n. 2, p. 449-55, maio/ago. 2004.

SAYAD, Abdelmalek. A imigração, ou, Os paradoxos da alteridade. São Paulo: EDUSP, 1998.

SCHADEN, Egon. A obra científica de Paul Ehrenreich. Revista de Antropologia, v. 12, n. 1/2, p. 83-86, jul./dez. 1964.

SCHLOUTAUER, Andreas. Munduruku and Apiaká Featherwork in the Johann Natterer Collection. In: Archiv für Völkerkunde 63-64.Viena: Lit Verlag, 2014. p. 133-162.

SEYFERTH, Giralda. A invenção da raça e o poder discricionário dos estereótipos. Anuário Antropológico. Rio de Janeiro: Edições Tempo Brasileiro, 1993. p. 175-203.

THOMPSON, Ana Lucia. A coleção Natterer: Objetos indígenas brasileiros. 2011. 305 f. Tese (Doutorado em Museologia) - Departamento de Museologia, Universidade Lusófona de Humanidades e Tecnologias, Lisboa, 2011.

VANZOLINI, Paulo Emílio. A contribuição zoológica dos primeiros naturalistas viajantes no Brasil. Revista USP, São Paulo, v. 30, p. 190-238,jun./ago. 1996.

WIED-NEUWIED, Maximiliano. Viagem ao Brasil (1815 a 1817). São Paulo: Companhia Editora Nacional, 1942. 


\title{
About Indian skulls, languages and artifacts: Collecting and Natural History on the journey of Johann Natterer to Brazil (1817-1835)
}

\begin{abstract}
This article aims to explore the collecting practices of Indian skulls, languages and artifacts realized by Johann Natterer in his trip to Brazil (1817-1835). Realized with in the framework of the Austrian scientific commission (largest scientific undertaking ever undertaken), Natterer was a pioneer in the formation of collections in the region of Mato Grosso and Rio Negro. Given the size of his trip, for the article presented, were selected three major sets of ethnographic situations that allow to reflect on the generalized use of the category 'naturalist' to index collections co-produced by a network of unequally socially positioned social actors: indigenous (free and slaves), militia chiefs, lieutenants, provincial governors, etc. In addition to pluralizing the 'naturalistic' category, the article also proposes to think about the connections between collecting in the context of Natural History and ethnography.
\end{abstract}

Keywords: Collecting, Natural History, Johann Natterer, ethnographic situations, ethnography.

\section{Sobre cráneos, idiomas y artefactos indígenas: El coleccionismo y la Historia Natural en el viaje de Johann Natterer a Brasil (1817-1835)}

\section{Resumen}

El presente artículo busca explorar las prácticas coleccionistas de cráneos, idiomas y artefactos indígenas llevados a cabo por Johann Natterer en su viaje a Brasil (1817-1835). Realizado en el marco de la comisión científica austríaca (mayor emprendimiento científico hasta entonces realizado), Natterer fue pionero en la formación de colecciones en la región de Mato Grosso y Río Negro. Dada la dimensión de su viaje, para el artículo presentado se seleccionaron tres grandes conjuntos de situaciones etnográficas que permiten reflexionar sobre el uso generalizado de la categoría "naturalista" para indexar colecciones coproducidas por una red de actores sociales desigualmente posicionados socialmente: indígenas (libres y esclavos), jefes de milicias, tenientes, gobernadores de provincia, etc. Además de pluralizar la categoría "naturalista", el artículo propone también pensar las conexiones entre el coleccionismo en el ámbito de la Historia Natural y la etnografia.

Palabras clave: Coleccionismo, Historia Natural, Johann Natterer, situaciones etnográficas, etnografia. 